\title{
Organizaciones policiales frente a la pandemia: sensemaking, liderazgo y discrecionalidad
}

\author{
Gustavo Matarazzo 12 \\ Alan Fernandes 23 \\ Rafael Alcadipani 2 \\ 1 Instituto Federal de Educação, Ciência e Tecnologia de São Paulo, São Paulo, SP - Brasil \\ 2 Fundação Getulio Vargas / Escola de Administração de Empresas de São Paulo, São Paulo, SP - Brasil \\ 3 Polícia Militar do Estado de São Paulo, São Paulo, SP - Brasil
}

\begin{abstract}
Hacer frente a la pandemia de COVID-19 se está convirtiendo en uno de los mayores desafíos recientes que enfrenta la humanidad. Entre las instituciones públicas especialmente activadas, la policía está posicionada en primera línea. En función de sus características organizativas y profesionales, las estrategias para hacer frente a la pandemia se discuten mediante el desarrollo de nuevas habilidades organizativas que les permitan cambiar su lógica operativa de "guerra contra el crimen" a acciones humanitarias. Por lo tanto, señala la necesidad de una coordinación sistémica de los cuerpos policiales, tanto entre ellos como en el conjunto de otras medidas de afrontamiento. En estos términos, a partir del análisis de diferentes experiencias, se propone formar una articulación interorganizacional basada en la creación de elementos lingüísticos y materiales, con el intercambio de mapas estratégicos y planes informativos. Por lo tanto, se concluye que la revisión de los protocolos de desempeño policial en emergencias de salud pública, incluido el Plan de Respuesta a Emergencias de Salud Pública, del Ministerio de Salud, tiene la capacidad de proporcionar avances en este tema.

Palabras clave: COVID-19; policía; sensemaking.
\end{abstract}

\section{Organizações policiais frente à pandemia: sensemaking, liderança e discricionariedade}

O enfrentamento da pandemia da COVID-19 desponta como um dos maiores desafios recentes impostos à humanidade. Dentre as instituições públicas especialmente acionadas, as polícias estão posicionadas na linha de frente. A partir de suas características organizacionais e profissionais, discute-se estratégias de enfrentamento à pandemia por meio do desenvolvimento de novas habilidades organizacionais que propiciem alterar suas lógicas de funcionamento de "guerra contra o crime" para ações humanitárias. Assim, aponta-se a necessidade de coordenação sistêmica dos órgãos policiais, tanto entre em si, como no conjunto das demais medidas de enfrentamento. Nesses termos, a partir da análise de experiências diversas, propõe-se a formação de uma articulação interorganizacional fundamentada na criação de elementos linguísticos e materiais, com o compartilhamento de mapas estratégicos e planos informacionais. Para tanto, conclui-se que a revisão de protocolos de atuação das polícias em emergências de saúde pública, a incluir o Plano de Resposta em Emergências em Saúde Pública, do Ministério da Saúde, tem a capacidade de prover avanços nessa questão.

Palavras-chave: COVID-19; polícia; sensemaking.

\section{Police institutions in the face of the pandemic: sensemaking, leadership, and discretion}

Coping with the COVID-19 pandemic is emerging as one of the greatest recent challenges facing humanity. The police forces are at the front line, among the public institutions specially activated in this emergency. Based on police forces' organizational and professional characteristics, this study discusses strategies to deal with the pandemic through the development of new organizational skills that allow them to change their operating logic from "war against crime" to humanitarian actions. The research points out the need for systemic coordination of police bodies, both among themselves and in the set of other coping measures. In these terms, from the analysis of different experiences, it is proposed to form inter-organizational coordination based on the creation of linguistic and material elements, with the sharing of strategic maps and informational plans. In conclusion, the review of police performance protocols in public health emergencies, including the Public Health Emergency Response Plan of the Ministry of Health, has the capacity to improve its response in the face of the COVID-19 pandemic. Keywords: COVID-19; police; sensemaking. 


\section{INTRODUCCIÓN}

La pandemia de COVID-19 está emergiendo como uno de los mayores desafíos en la historia reciente de la humanidad. La propagación del virus ha llevado a las instituciones del Estado, especialmente a aquellas directamente involucradas en la gestión de la población, a implementar el aislamiento social para mitigar el contagio. En este contexto, se evoca el papel de las fuerzas de seguridad pública para garantizar la gobernabilidad, especialmente en lo que se refiere al cumplimiento de la medida obligatoria de aislamiento social y a la seguridad del personal y del equipamiento de salud, directamente relacionados con la profilaxis de la enfermedad. En Brasil, la Policía ha actuado en la investigación de hurtos y robos de equipamiento de protección personal contra el virus y de pruebas de detección de la enfermedad; en la investigación de fraude de equipamiento y procesos de licitación; en la fiscalización del cumplimiento de las normas de funcionamiento de las actividades económicas, e incluso en el arresto de personas que no respetan las disposiciones.

La Policía es una de las categorías de la primera línea en la lucha contra la pandemia más vulnerables al contagio. Por ejemplo, en Nueva York - gran foco de la enfermedad -, hasta el 7 de abril de 2020, casi el 20\% del contingente policial había sido infectado por el virus y doce miembros habían muerto. En Brasil, todavía no hay estudios al respecto. Sin embargo, una encuesta realizada por la Fundação Getúlio Vargas en alianza con el Fórum Brasileiro de Segurança Pública (Foro Brasileño de Seguridad Pública) publicada en mayo de 2020 muestra que, en São Paulo, el 59,7\% de los agentes de la Policía Civil y Militar tiene miedo de contraer el nuevo coronavirus o de tener un familiar contaminado y, lo peor de todo, solo $1 / 3$ de los policías en Brasil informó haber recibido equipamiento de protección individual y capacitación para enfrentar la pandemia en su trabajo cotidiano.

Las organizaciones policiales se caracterizan por un fuerte contenido cognitivo interno, una cultura organizacional muy peculiar y culturas ocupacionales específicas (Rubinstein, 1973; Manning, 1977). El escenario actual de la pandemia de COVID-19 impone un cambio de perspectiva en la acción policial, que siempre privilegió el modelo de acción de "lucha contra el crimen". En este contexto, se considera necesario debatir sobre la adopción de modelos de gestión interna y de prácticas más apropiados y dirigidos a acciones humanitarias (Alcadipani, 2020b; Alcadipani, Cabral, Fernandes, \& Lotta, 2020). Las organizaciones de "primera línea", como las policiales, necesitan implementar urgentemente cambios organizativos para enfrentar la pandemia, teniendo en cuenta una multiplicidad de factores: biológicos, sociales y políticos aquí citados.

Por lo tanto, el presente artículo discute las estrategias de afrontamiento de la pandemia por parte de la Policía, y propone el desarrollo de nuevas habilidades organizativas, impulsando los esfuerzos para elaborar un modelo de actuación que coordine las diferentes agencias y garantice un nuevo sentido a la actuación de las corporaciones policiales. Para ello, estructuramos este artículo con una sección, posterior a la introducción, que enfoca la coordinación sistémica de las acciones de diferentes agencias. Luego, discutimos la necesidad de alterar la producción de sentidos de la Policía, como el enfoque específico en cuestiones de discrecionalidad y emoción. Finalmente, discutimos sugerencias de elementos prácticos que la Policía puede adoptar para enfrentar la pandemia.

\section{COORDINACIÓN SISTÉMICA E INCLUSIÓN DE LA POLICÍA EN EL AFRONTAMIENTO DE LA PANDEMIA}

En los estudios de burocracia, en comparación con otras organizaciones del Estado, la Policía constituye un ejemplo evidente de apartamiento, motivado por contenidos cognitivos específicos que caracterizan formas propias de actuación (Giacomantonio, 2014; Mastrofski \&Willis, 2010; Monjardet, 
1998). En Brasil, por ejemplo, las Policías Civil y Militar tienen grandes dificultades para articular acciones conjuntas y compartir información, lo que denota la falta de instrumentos que promuevan un desempeño sistémico de las diferentes agencias policiales, así como un acuerdo más amplio que conecte diversas áreas estatales. En el contexto actual, los obstáculos intrínsecos inherentes a la lucha contra la pandemia se suman a la dificultad de coordinación interagencial en Brasil.

Contextos como el de la pandemia actual requieren decisiones rápidas y variadas, lo que implica recursos y presupuestos urgentes para la actuación de las organizaciones (Comes, 2016). Las respuestas a contextos como este tienden a encontrar problemas en los procesos comunicacionales, en el ejercicio de autoridad y en el desarrollo de coordinaciones (Quarantelli, 1988). Además, al considerar los procesos comunicacionales en las organizaciones policiales, identificamos que sus sistemas de tecnología de la información son difusos y, en general, no comparten las mismas bases de datos (Manning, 2008). En Brasil, el diálogo entre los sistemas de datos de la Policía Militar, Civil y Federal es aún más raro.

Para que las organizaciones actúen de manera coordinada es importante que los ocupantes de los puestos directivos compartan el mismo mapa estratégico del contexto en cuestión. El networking de los directores y comandantes de las organizaciones debe activarse para contribuir a crear y fortalecer los flujos de información a través de estructuras burocráticas adaptables (Stephenson, 2005). Sabemos que las organizaciones policiales están fuertemente apegadas a hábitos y costumbres (Manning, 2007, 2008), lo que puede crear obstáculos a la prontitud exigida por la actual situación. Por consiguiente, consideramos que es muy importante la actuación de analistas organizacionales, teniendo en vista la elaboración de ambientes y dispositivos propicios para la toma de decisión conjunta.

En resumen, la coordinación de acciones interorganizacionales es un aspecto fundamental a desarrollar entre las diferentes instituciones gubernamentales para enfrentar la pandemia. En Brasil, los gobiernos raramente entienden que la Policía puede contribuir al combate de la pandemia diariamente, analizando los flujos poblacionales - ya que cuenta con los instrumentos adecuados - y apoyando a los profesionales de la salud en la organización de las unidades de atención. La inclusión de la Policía en el sistema de gestión de la pandemia depende de la puesta a disposición de flujos de información similares a los de las demás organizaciones que están lidiando con la enfermedad.

En vista de esto, la construcción de sentidos (sensemaking) de las diversas organizaciones que trabajan para combatir la pandemia debe compartir un plan informativo que favorezca la interoperabilidad entre ellas. En el caso de la Policía, ese esfuerzo es aún más desafiante, ya que requiere la producción de nuevos sentidos, como discutiremos a continuación.

\section{PRODUCCIÓN DE SENTIDOS DE LA POLICÍA PARA LA PANDEMIA}

Comúnmente, se atribuye una lógica racional a la toma de decisiones de las organizaciones policiales. Sin embargo, dada la variedad de contextos en los que opera la Policía, surgen racionalidades específicas que no son evidentes ni autoexplicativas. Es decir, la "versión racional" existe, no obstante, se establece situacionalmente, de acuerdo con los contextos en los que se toman las decisiones (Manning, 1977, 2008). Este aspecto de los objetivos organizacionales es frecuentemente objeto de debate.

La indeterminabilidad de tales contextos conduce a fenómenos socio-organizacionales cuyo propósito es reducir tales ambigüedades (Baran \& Scott, 2010). Una forma de comprenderlos es a 
través de la noción de sensemaking, entendida como una forma de crear sentido clasificando los flujos de experiencias en categorías (Weick, Sutcliffe, \& Obstfeld, 2005).

Combatir el crimen y aplicar la ley son dos objetivos organizacionales de las instituciones policiales de todo el mundo. Este ámbito de acción está influenciado por las culturas organizacionales y ocupacionales de esas instituciones (Chan, 1997; Gowricharn \& Çankaya, 2017; Ingram, Terrill, \& Paoline, 2018; Reiner, 2016; Turnbull \& Wass, 2015). Es decir, combatir el crimen depende del contenido simbólico compartido entre los policías. Sin embargo, la dimensión simbólica del combate al crimen tiende a limitar la reacción de la Policía ante la pandemia, ya que el agente de policía generalmente tiene como sentido construido enfrentar el riesgo, diferentemente de lo que se debería hacer para lidiar con el virus (Alcadipani, 2020a; Alcadipani et al., 2020). Por lo tanto, la situación caótica resultante de la pandemia requiere nuevos encuadramientos para dar sentido a los procesos y acciones organizacionales.

Otros países, donde la COVID-19 se manifestó primeramente, utilizando la capilaridad de la Policía, agregaron funciones adicionales a su trabajo, tales como: recolección de material para análisis; estructuración de logística para movimiento de recursos específicos; y recopilación de datos para la elaboración de acciones estratégicas.

De acuerdo con Weick et al. (2005), el sensemaking es un proceso interaccional y cognitivo que comienza con el caos, pero que hace posible transformar las circunstancias en hitos para las acciones organizacionales. En el contexto policial, estamos tratando sobre los procesos de negociación de la realidad socio-organizacional (Manning, 2007). Además del clima mixto de incertidumbre, inseguridad y desorientación que ya está relacionado con la naturaleza extrema del trabajo policial (Granter, McCann, \& Boyle, 2015), la pandemia trae nuevos aspectos, especialmente relacionados con la dimensión biológica del contagio y la propagación del virus, una dimensión que no puede ignorarse al establecer sentidos para el funcionamiento de la Policía.

Los desafíos planteados por el escenario actual exigen que las fuerzas policiales comprendan que se trata de un momento de acción humanitaria, en el que el uso de la fuerza deja de ser protagonista de los modos de acción para dar lugar a la construcción de una gobernabilidad negociada. Para que los policías que operan en las calles se encuadren en este nuevo perfil, se necesitan dispositivos, lo que puede entenderse como el encadenamiento preparado de secuencias, cuyo objetivo es calificar o transformar los estados de cosas mediante el agenciamiento de elementos materiales y lingüísticos (Dodier \& Barbot, 2016). Los elementos materiales corresponden a los procesos y a los documentos administrativos que ayudan y guían la toma de decisiones de los "burócratas a nivel de la calle" (Lipsky, 2010), además del equipamiento de protección específico; y elementos lingüísticos, el conjunto de términos y narrativas basado en expertises de la salud, especialmente necesarias en este momento. Es decir, en momentos caóticos como el actual, las organizaciones y sus líderes deben crear dispositivos que ayuden a los sujetos a dar sentido a las situaciones y a los contextos. Además, es fundamental que los policías sean capacitados y comprendan los riesgos asumidos y la importancia de su trabajo para superar esta crisis, mediante flujos de información clara, científicamente fundamentada (Djalante, Shaw, \& DeWit, 2020).

Considerando el carácter humanitario que deben adoptar las reglas para el funcionamiento de las organizaciones y para la toma de decisiones, es importante que las organizaciones creen elementos lingüísticos y materiales que delineen claramente los contextos, con vistas a influir en la formación de sentido de sus miembros. En términos prácticos, se deben elaborar estándares y protocolos de atención, sin dejar de considerar la situación atípica de las personas infectadas asintomáticas (Zhou 
et al., 2020). A nivel administrativo-burocrático, las acciones deben garantizar, por ejemplo, un presupuesto para el suministro de material de protección individual y colectiva a las unidades.

Dicho esto, el sensemaking no significa producir una narrativa única de lo que está sucediendo, sino que presenta puntos de apoyo convencionales para el desarrollo de las acciones. Varios condicionantes influyen en este proceso, y el papel del liderazgo es fundamental, principalmente en las organizaciones policiales, dadas sus características jerárquico-organizativas. Desarrollaremos este aspecto en la última parte del artículo.

\section{DISCRECIONALIDAD Y EMOCIÓN: POLICÍA EN TIEMPOS DE PANDEMIA}

Las experiencias son irreductibles (James, 1904), es decir, no pueden considerarse predominantemente por un solo aspecto, ya sea cognitivo o sensorial. Considerar los procesos antes mencionados como eminentemente racionales, apartándolos de las dimensiones corporal y emocional, es en nuestra opinión un error, sobre todo en el momento actual. Las emociones tienen lugar en los cuerpos. Por lo tanto, ellos son dimensiones de la creación de sentido, lo que resulta en la influencia de las emociones en los procesos de sensemaking (Maitlis, Vogus, \& Lawrence, 2013). De esta manera, los estados corporales afectan y son afectados por la situación; además, las investigaciones sobre cognición incorporada demuestran que los procesos cognitivos se basan en los cuerpos (Hernes \& Maitlis, 2010; Maitlis \& Sonenshein, 2010). En el caso de la Policía, todas las cuestiones planteadas deben considerarse en relación con el cuerpo, un elemento importante de la identidad del trabajo policial (Courpasson \& Monties, 2017).

En vista de lo expuesto anteriormente, el cuerpo, en el caso de la pandemia, comienza a recibir una carga valorativa: es tanto la dimensión por la cual hay proliferación del virus y contagio de la enfermedad - que, por lo tanto, requiere atención específica -, como es por medio de él y de las emociones - que se pondrán a prueba cada vez más debido a la enfermedad que afectará al propio policía, a sus compañeros de trabajo y a sus familiares - que se deben construir los arreglos institucionales. Por estas razones, las organizaciones deben plantear inquietudes concernientes a la salud física y mental en el trabajo, principalmente debido a las crecientes tasas de contaminación que promoverán una disminución de la fuerza laboral.

Para complementar, no se pueden crear discursos que alienten el trabajo a cualquier costo; un policía con sospecha de contaminación (o que resida con alguien sospechoso) debe cumplir estrictamente con las recomendaciones de las organizaciones de salud y apartarse del trabajo; de lo contrario, representa un riesgo para los otros miembros de la Policía y también para sus familias. La tasa de contagio de la enfermedad es alta (Zhou et al., 2020), y la exposición irresponsable de los policías al contagio puede resultar en regiones enteras sin sus contingentes policiales activos.

Aunque se trate de organizaciones con trabajos con un alto nivel de estrés (Granter et al., 2015), es importante destacar que esta crisis no tiene precedentes. Por lo tanto, es probable que muchos se infecten, lo que conducirá a la disminución de los contingentes y aumentará el trabajo diario relacionado con las tareas establecidas de combate al crimen y atención a llamadas de emergencia, ya que, en momentos como este, de reconfiguración de los flujos de personas y capitales, tienden a surgir nuevas formas de conflicto y delincuencia, lo que plantea nuevos retos a las corporaciones.

Los policías son burócratas a nivel de la calle, es decir, trabajan directamente con los ciudadanos y tienen una discreción sustancial en sus actividades (Lipsky, 2010). Tal discrecionalidad a menudo es tratada con desconfianza por las estructuras e instancias de control (Cavalcanti, Lotta, \& Pires, 2018). 
El espacio de discrecionalidad se refiere a las perspectivas organizacionales, así como a la relación entre superiores y subordinados; por otro lado, la acción de discrecionalidad se da por la forma en que los burócratas entienden los contenidos normativos (Lotta \& Santiago, 2017).

Ante este escenario, es fundamental que el cuerpo directivo de las organizaciones policiales mapee $y$, cuando sea posible, delinee el espacio de discrecionalidad a los efectos de garantizarles seguridad administrativa y legal a las tomas de decisión a nivel local. La obtención de materiales debe llevarse a cabo, siempre que sea posible, por las estructuras organizacionales directamente involucradas en el afrontamiento de la pandemia. Las investigaciones en el sector muestran que, en lugar de que tales estructuras organizacionales lleven a cabo dicha tarea, existen organismos burocráticos intermediarios para este propósito, por ejemplo, los centros responsables de las compras, unidades regionales, seccionales y estructuras específicas. La justificación para este escenario de centralización es la mayor posibilidad de control. No obstante, los actores relatan falta de celeridad. En este sentido, entendemos que es necesario descentralizar la gestión de parte del presupuesto para garantizar la atención de las organizaciones y de los policías.

\section{POLICÍA Y PANDEMIA: ¿QUÉ HACER?}

Con base en lo anteriormente expuesto, preguntamos: ¿qué puede hacer la Policía brasileña en un escenario de pandemia? Las emergencias públicas requieren una rápida adaptación a condiciones inestables, gestión de la distribución de información, coordinación bilateral y acción colectiva emergente (Nowell, Steelman, Velez, \& Yang, 2018). En Brasil, la falta de coordinación política contribuye a la descentralización del trabajo de las corporaciones policiales en el combate al virus e impone constricciones políticas, materiales y culturales que inmovilizan a las corporaciones y perjudican su trabajo con la población (Alcadipani et al., 2020; Lotta et al., 2020).

Las experiencias de otros países demuestran la necesidad de una articulación interorganizacional para que las corporaciones policiales se movilicen para enfrentar la pandemia, ya sea creando mecanismos de coordinación o activando los existentes (Djalante et al., 2020; Legido-Quigley et al., 2020; Nkengasong \& Mankoula, 2020; Zhao et al., 2020). Brasil tiene un Plan de Respuesta a Emergencias de Salud Pública (Ministério da Saúde, 2014), originario del Ministerio de Salud del Gobierno Federal, diseñado para coordinar esfuerzos en caso de crisis de salud pública en ámbito nacional e internacional. El plan prevé la activación de un Centro de Emergencia de Salud Pública (COES) para "[...] promover una respuesta coordinada a través de la articulación e integración de los actores involucrados" (Ministério da Saúde, 2014, p. 14), con la institución previa de protocolos de acción para estos actores. Sin embargo, esta articulación solo incluye actores vinculados al campo de la salud, sin cotejar la promoción de enforcement. Este plan difiere, por ejemplo, del estadounidense que, en casos de amenaza a la salud pública, dispone de instrumentos institucionales de coordinación de las fuerzas policiales con las autoridades sanitarias (Richards, Rathburn, Brito, \& Luna, 2006).

Señalamos, así, la necesidad de profundizar el Plan de Respuesta a Emergencias de Salud Pública, dotándolo de un alcance que incluya al trabajo policial en las medidas sanitarias. Dicho escenario permitiría una mayor capacidad de coordinación nacional de esfuerzos, tendría el potencial de atender los problemas suscitados en este trabajo, al darle un nuevo sensemaking a los arreglos policiales locales y garantizaría aspectos de constitución de una legitimidad necesaria a las acciones demandadas, reorientando las prácticas policiales ya consolidadas en su labor cotidiana. No obstante, esta es una acción a largo plazo, que movilizaría a muchos actores políticos que, en Brasil, están en una posición de divergencia y conflicto. 
A corto plazo, vale observar los ejemplos de otras corporaciones policiales del mundo, considerando la investigación "La pandemia de COVID-19 y los policías brasileños" (2020) que muestra que el 43,9\% de los policías no se sentía preparado y el 24,5\% no sabía responder cómo actuar en la pandemia (Lotta et al., 2020). En la India, en una actitud de carácter humanitario, la Policía está tratando de resignificar su relación con las personas, actuando en el auxilio a las víctimas de la pandemia y en la asistencia a la población en general (Gettleman, Singh, Kim, \& Kumar, 2020). En todo el mundo y en Brasil, numerosos departamentos policiales han instituido protocolos que regulan cómo los policías deben abordar sospechosos, interrogar a testigos y transportar prisioneros. El College of Policing del Reino Unido y la Interpol han compartido guías y protocolos específicos para la actuación policial durante la pandemia, que abordan diferentes dimensiones del trabajo. La realización de videos cortos que muestran los protocolos en la práctica puede ser una forma rápida de difundir el uso de equipamiento de protección individual, como lo ha hecho la Policía Militar de São Paulo (PMTV, 2020).

Desde esta lógica, es esencial identificar a los policías con síntomas de contaminación para evitar el contagio de los otros agentes y de sus familiares. Mediante la realización de pruebas rápidas en todos los profesionales de la Policía es posible identificar a aquellos que tuvieron contacto con el virus y que, por esta razón, deben ser apartados de sus actividades. Pero la pandemia provocó el problema de escasez de pruebas en todo el mundo (Ranney, Griffeth, \& Jha, 2020). La imposibilidad de acceso a los test y la contaminación de los agentes, después de la realización de dichos test, hacen necesarias medidas complementarias, como la verificación de los niveles de oxígeno y de la temperatura de todos los policías que llegan al trabajo, como ya se ha hecho en EE.UU. y en Europa. La identificación de un policía contaminado requiere su aislamiento durante 14 días. En algunos lugares, se han utilizado hoteles para evitar la transmisión del virus a su familia y, si la enfermedad empeora, el policía puede ser atendido de inmediato.

También es importante que las corporaciones practiquen, en la medida de lo posible, la distancia social entre los policías en las unidades y entre los policías y el público; y prioricen la atención de emergencias y el patrullaje, pero siguiendo protocolos específicos que determinen cuándo debe llevarse a cabo el abordaje policial. Reorganizar las tareas para que la interacción con la población se realice virtualmente es una medida de protección importante para los policías. En São Paulo, la Policía Civil comenzó a registrar online una mayor variedad de delitos y también creó una comisaría electrónica para mujeres, con atención brindada por estudiantes de la Academia de Policía. Por lógica, los policías deberían comparecer a sus lugares de trabajo solo cuando fuera necesario. Además, hay corporaciones policiales fuera de Brasil que han creado fuerzas operativas para cubrir la ausencia de agentes que están en aislamiento por la enfermedad. Es importante suspender todas las ceremonias presenciales de las instituciones, según lo adoptado por la Policía Militar de São Paulo. Asimismo, hay instituciones policiales que están cambiando los turnos de trabajo con el objetivo de ayudar al distanciamiento social y, así, reducir el número de personas que comparten espacios al mismo tiempo.

El afrontamiento de crisis destaca los roles de los líderes organizacionales, ya que influyen en las condiciones que definen las situaciones y en las formas de comprenderlas (Whittle, Housley, Gilchrist, Mueller, \& Lenney, 2015), así como también ayudan en el proceso de producción de sentidos dentro de las organizaciones. Los estudios indican que la creación de sentido por parte de los líderes es un proceso que no siempre cumple con la velocidad de los hechos experimentados; por cierto, la formación de consenso y la sensibilización de los individuos involucrados requieren un determinado tiempo (Combe \& Carrington, 2015). La discusión sobre el papel del liderazgo es aún más fundamental en las organizaciones policiales, que se basan en jerarquías. 
Los líderes organizacionales y políticos deben ajustar sus discursos y buscar fundamentos en campos de expertises más consolidadas, corroborados por la técnica y la ciencia ("Coronavirus: three things all governments and their science advisers must do now”, 2020). Así, los líderes encontrarán más posibilidades de promover nuevos contextos que se adapten a las necesidades que surgirán con el desarrollo de la pandemia, apoyando los cambios organizacionales. A ese respecto, la profusión de información falsa (fakenews) y/o de poca credibilidad en las redes sociales crea dificultades para el liderazgo y para la construcción cognitiva de nuevos ambientes. Por lo tanto, el papel del liderazgo es importante para guiar los encuadramientos, sin dudas ni confusiones acerca de las acciones. Las organizaciones policiales que están respondiendo mejor al desafío son aquellas cuyos líderes internos han asumido el papel protagónico: primero, reconociendo la gravedad de la enfermedad para las fuerzas policiales y la necesidad de trabajar de manera diferente frente a la pandemia y, después, dando el ejemplo de adopción de protocolos de seguridad y comunicando frecuentemente a los agentes de policía sobre qué camino tomar. De esta manera, los líderes policiales deben dejar claro que el momento de la pandemia de COVID-19 es excepcional: en esta situación, solo las emergencias policiales deben movilizar los esfuerzos de sus instituciones, el distanciamiento social debe ser tomado en serio dentro de las organizaciones policiales. Además, sus líderes necesitan orientar a sus organizaciones para que trabajen mucho más como instituciones de apoyo humanitario que como instrumentos de combate al crimen.

\section{CONSIDERACIONES FINALES}

La pandemia de COVID-19 parece ser el mayor desafío que enfrenta la humanidad desde la Segunda Guerra Mundial. Nos proporciona la experiencia de la incertidumbre del mundo y de nuestra relación con la naturaleza (Dewey, 1958; James, 1904). Esas cuestiones colisionan brutalmente con la lógica operativa de las organizaciones, especialmente en lo que se refiere a las perspectivas de la racionalidad, de los objetivos y de los sentidos construidos organizacionalmente.

En este artículo, buscamos evidenciar que el trabajo de la Policía debe pasar por cambios para enfrentar la pandemia mundial, lo que requiere esfuerzos para garantizar que las organizaciones policiales se incluyan en las coordinaciones interinstitucionales. Para ello, señalamos que las estructuras más capilares de esas organizaciones necesitan apoyos variados.

Asimismo, además de la cuestión de gestión de poder en la organización, son importantes los sentidos que guían los cambios necesarios y la construcción de nuevos dispositivos materiales y lingüísticos que promuevan nuevos encuadramientos de actuación de la Policía. Es necesario que las organizaciones policiales cambien su lógica operativa, pasando de la noción de "guerra contra el crimen" a la de acciones humanitarias (Alcadipani, 2020c).

Por lo tanto, es imperativo que las organizaciones se ajusten a través de un mismo plan informativo, presentando narrativas alineadas entre sí, desarrollando métodos y sentidos organizacionales que establezcan la seguridad pública como una acción humanitaria.

Las emociones y la discrecionalidad son aspectos a considerar, especialmente por los profesionales que trabajan en la primera línea de combate a la pandemia. Consideramos, por lo tanto, que esas organizaciones se constituirán en herramientas afrontamiento de esta crisis y podrán ver en esta situación una ventana de oportunidad para establecer nuevas relaciones con sus públicos. Como lo demuestra el caso de la India, actuar promoviendo la acción humanitaria puede acercar la Policía a la sociedad, un factor fundamental para el buen funcionamiento de cualquier política de seguridad pública. 


\section{REFERENCIAS}

Alcadipani, R. (2020a). Pandemic and macho organizations: wakeup call or business as usual? Gender, Work \& Organization, Early view, 1-13. Recuperado de https://doi.org/10.1111/gwao.12466

Alcadipani, R. (2020b, 05 de marzo). El coronavirus y los impactos en la seguridad pública. Estadão. Recuperado de https://politica.estadao.com.br/ blogs/gestao-politica-e-sociedade/o-coronaviruse-os-impactos-para-a-seguranca-publica/

Alcadipani, R. (2020c, 20 de marzo). El coronavirus y el colapso del sistema de seguridad pública. Estadão. Recuperado de https://politica.estadao.com.br/ blogs/gestao-politica-e-sociedade/o-coronavirus-eo-colapso-do-sistema-de-seguranca-publica/

Alcadipani, R., Cabral, S., Fernandes, A., \& Lotta, G. (2020, junio). Street-Level bureaucrats under COVID-19: police officers' responses in constrained settings. Administrative Theory \& Praxis, 1-10. Recuperado de https://doi.org/10.1080/10841806. 2020.1771906

Baran, B. E., \& Scott, C. W. (2010, enero). Organizing ambiguity: a grounded theory of leadership and sensemaking within dangerous contexts. Military Psychology, 22 (Suppl. 1), S42-S69. Recuperado de https://doi.org/10.1080/08995601003644262

Cavalcanti, S., Lotta, G. S., \& Pires, R. R. C. (2018). Contribuições dos estudos sobre burocracia de nível de rua. In R. Pires, G. S. Lotta, \& V. E. Oliveira (Orgs.), Burocracia e políticas públicas no Brasil: interseções analíticas (pp. 227-246). Brasília, DF: Ipea/Enap. Recuperado de http://repositorio.enap. gov.br/bitstream/1/3247/1/livro_Burocracia e políticas públicas no Brasil - interseções analíticas. pdf

Chan, J. B. L. (1997). Changing police culture. Policing in a multicultural society. Cambridge, UK: Cambridge University Press.

Combe, I. A., \& Carrington, D. J. (2015). Leaders' sensemaking under crises: emerging cognitive consensus over time within management teams. Leadership Quarterly, 26(3), 307-322. Recuperado de https://doi.org/10.1016/j.leaqua.2015.02.002

Comes, T. (2016, marzo). Cognitive biases in humanitarian sensemaking and decision-making lessons from field research. Proceedings of 2016
IEEE International Multi-Disciplinary Conference on Cognitive Methods in Situation Awareness and Decision Support, (pp. 56-62), San Diego, CA. Recuperado de https://doi.org/10.1109/ COGSIMA.2016.7497786

Coronavirus: three things all governments and their science advisers must do now. (2020, 17 de marzo). Nature, 579(7799), 319-320. Recuperado de https:// doi.org/10.1038/d41586-020-00772-4

Courpasson, D., \& Monties, V. (2017). "I am my body". Physical selves of police officers in a changing institution. Journal of Management Studies, 54(1), 32-57. Recuperado de https://doi.org/10.1111/ joms. 12221

Dewey, J. (1958). Experience and nature. New York, NY: Dover.

Djalante, R., Shaw, R., \& DeWit, A. (2020, abril). Building resilience against biological hazards and pandemics: COVID-19 and its implications for the Sendai Framework. Progress in Disaster Science, 6, 100080. Recuperado de https://doi.org/10.1016/j. pdisas.2020.100080

Dodier, N., \& Barbot, J. (2016). La force des dispositifs. Annales. Histoire, Sciences Sociales, 71(02), 421-448. Recuperado de https://doi. org/10.1353/ahs.2016.0064

Gettleman, J., Singh, K. D., Kim, C., \& Kumar, H. (2020, 01 de Junio). How India's Police Used a Pandemic to Boost Its Image. NYTIMES. Recuperado de https://www.nytimes.com/video/ world/100000007141490/-india-police-pandemiccoronavirus.html ?action $=$ click \&gtype $=$ vhs \&ver sion $=$ vhs - heading $\&$ module $=$ vhs $\&$ region $=$ title area\&cview $=$ true $\& \mathrm{t}=4$

Giacomantonio, C. (2014). A typology of police organizational boundaries. Policing and Society, 24(5), 545-565. Recuperado de https://doi.org/10.1 080/10439463.2013.784302

Gowricharn, R., \& Çankaya, S. (2017). Policing the Nation: acculturation and streetlevel bureaucrats in professional life. Sociology, 51(5), 1101-1117. Recuperado de https://doi. org/10.1177/0038038515601781

Granter, E., McCann, L., \& Boyle, M. (2015). Extreme work/normal work: intensification, storytelling and hypermediation in the (re)construction of 'the New 
Normal'. Organization, 22(4), 443-456. Recuperado de https://doi.org/10.1177/1350508415573881

Hernes, T., \& Maitlis, S. (2010). Process, sensemaking, and organizing: an introduction. In T. Hernes \& S. Maitlis (Eds.), Process, Sensemaking, \& Organizing (Perspectiv, pp. 27-37). New York, NY: Oxford University Press.

Ingram, J. R., Terrill, W., \& Paoline, E. A. (2018). Police culture and officer behavior: application of a multilevel framework. Criminology, 56(4), 780811. Recuperado de https://doi.org/10.1111/17459125.12192

James, W. (1904). The world of pure experience. The Journal of Philosophy, Psychology and Scientific Methods, 1(20), 533-543.

Latour, B. (2012). Reagregando o social: uma introdução à teoria do Ator-Rede. Salvador, BA: EDUFBA; EDUSC.

Legido-Quigley, H., Mateos-García, J. T., Campos, V. R., Gea-Sánchez, M., Muntaner, C., \& McKee, M. (2020). The resilience of the Spanish health system against the COVID-19 pandemic. The Lancet Public Health, 5(5), e251-e252. Recuperado de https://doi. org/10.1016/S2468-2667(20)30060-8

Lipsky, M. (2010). Street-level democracy: dilemmas of the individual in public services (30th anniv.). New York, NY: Russell Sage Foundation.

Lotta, G., \& Santiago, A. (2017). Autonomia e discricionariedade: matizando conceitos-chave para o estudo da burocracia. BIB, 1(83), 21-42.

Lotta, G., Sobral, I., Corrêa, M., Alcadipani, R., \& Bueno, S. (2020, 18 de mayo). A pandemia de Covid-19 e os policiais brasileiros (Nota técnica). São Paulo, SP: Fórum Brasileiro de Segurança Pública. Recuperado de https://forumseguranca.org.br/ publicacoes_posts/a-pandemia-de-covid-19-e-ospoliciais-brasileiros/

Maitlis, S., \& Sonenshein, S. (2010). Sensemaking in crisis and change: inspiration and insights from Weick (1988). Journal of Management Studies, 47(3), 551-580. Recuperado de https://doi.org/10.1111/ j.1467-6486.2010.00908.x

Maitlis, S., Vogus, T. J., \& Lawrence, T. B. (2013). Sensemaking and emotion in organizations. Organizational Psychology Review, 3(3),
222-247. Recuperado de https://doi. org/10.1177/2041386613489062

Manning, P. K. (1977). Police work: the social organization of policing. Cambridge, UK: MIT Press.

Manning, P. K. (2007). A dialectic of organisational and occupational culture. In M. O'Neill, M. Marks, \& A.-M. Singh (Eds.), Police occupational culture: new debates and directions (pp. 47-84). Oxford, UK: JAI Press. Recuperado de https://doi.org/10.1016/ S1521-6136(07)08002-5

Manning, P. K. (2008). The technology of policing: crime mapping, information technology, and the rationality of crime control. New York, NY: New York University Press.

Mastrofski, S. D., \& Willis, J. J. (2010). Police organization continuity and change: into the twenty-first century. Crime and Justice, 39, 55-144. Recuperado de https://doi.org/10.1086/653046

Ministério da Saúde. Secretaria de Vigilância em Saúde. Departamento de Vigilância em Saúde Ambiental e Saúde do Trabalhador. (2014). Plano de Resposta às Emergências em Saúde Pública. Brasília, DF: Autor.

Monjardet, D. (1998). Elementos de análisis de los sistemas policiales. Revista Catalana de Seguretat Pública, 2, 179-194.

Nkengasong, J. N., \& Mankoula, W. (2020). Looming threat of COVID-19 infection in Africa: act collectively, and fast. The Lancet, 395(10227), 841-842. Recuperado de https://doi.org/10.1016/ S0140-6736(20)30464-5

Nowell, B., Steelman, T., Velez, A. L. K., \& Yang, Z. (2018). The structure of effective governance of disaster response networks: insights from the field. American Review of Public Administration, 48(7), 699-715. Recuperado de https://doi. org/10.1177/0275074017724225

PMTV. (2020, 17 de abril). Atuação da PMESP em tempos de COVID-19. Youtube. Recuperado de https://www.youtube.com/watch?v=T2Xn21xowP0

Quarantelli, E. L. (1988). Disaster crisis management. Journal of Management Studies, 25(4), 373-385. Recuperado de https://doi. org/10.1111/j.1467-6486.1988.tb00043.x 
Ranney, M. L., Griffeth, V., \& Jha, A. K. (2020). Critical supply shortages - the need for ventilators and personal protective equipment during the Covid-19 pandemic. New England Journal of Medicine, 382(18), e41(1)-e41(3). Recuperado de https://doi.org/10.1056/NEJMp2006141

Reiner, R. (2016, 05 de diciembre). Is police culture cultural? Policing, (Opinion), 11(3), 236-241. Recuperado de https://doi.org/10.1093/police/ paw046

Richards, E. P., Rathburn, K. C., Brito, C. S., \& Luna, A. (2006). The Role of Law Enforcement in Public Health Emergencies. Washington, DC: U.S. Department of Justice.

Rubinstein, J. (1973). City Police. New York, NY: Farrar, Straus and Giroux.

Stephenson, M., Jr. (2005). Making humanitarian relief networks more effective: operational coordination, trust and sense making. Disasters, 29(4), 337-350. Recuperado de https://doi. org/10.1111/j.0361-3666.2005.00296.x

Turnbull, P. J., \& Wass, V. (2015). Normalizing extreme work in the Police Service? Austerity and the inspecting ranks. Organization, 22(4), 512-529. Recuperado de https://doi. org/10.1177/1350508415572513

Weick, K. E., Sutcliffe, K. M., \& Obstfeld, D. (2005). Organizing and the Process of Sensemaking. Organization Science, 16(4), 409-421. Recuperado de https://doi.org/10.1287/orsc.1050.0133

Whittle, A., Housley, W., Gilchrist, A., Mueller, F., \& Lenney, P. (2015). Category predication work, discursive leadership and strategic sensemaking. Human Relations, 68(3), 377-407. Recuperado de https://doi.org/10.1177/0018726714528253

Zhao, W., Zhang, J., Meadows, M. E., Liu, Y., Hua, T., $\& \mathrm{Fu}$, B. (2020, 15 de junio). A systematic approach is needed to contain COVID-19 globally. Science Bulletin, 65(11), 876-878. Recuperado de https:// doi.org/10.1016/j.scib.2020.03.024

Zhou, F., Yu, T., Du, R., Fan, G., Liu, Y., Liu, Z., ... Cao, B. (2020, 09 de marzo). Clinical course and risk factors for mortality of adult inpatients with COVID-19 in Wuhan, China: a retrospective cohort study. The Lancet, 395, 1054-1055. Recuperado de https://doi.org/10.1016/S0140-6736(20)30566-3

\section{Gustavo Matarazzo}

https://orcid.org/0000-0002-4640-3863

Posdoctorando en Administración de la Escola de Administração de Empresas de São Paulo (EAESP) de la Fundação Getulio Vargas (FGV); Profesor del Instituto Federal de Educação, Ciência e Tecnologia de São Paulo (IFSP) Campus Capivari. E-mail: gustavo.matarazzo@ifsp.edu.br

\section{Alan Fernandes}

\section{https://orcid.org/0000-0003-1364-3868}

Doctorando en Administración de la Escola de Administração de Empresas de São Paulo (EAESP) de la Fundação Getulio Vargas (FGV); Mayor de la Policía Militar del Estado de São Paulo.

E-mail: alan@policiamilitar.sp.gov.br

\section{Rafael Alcadipani}

https://orcid.org/0000-0001-5132-5380

Doctor en Management Sciences de la Manchester Business School; Profesor titular de la Escola de Administração de Empresas de São Paulo (EAESP) de la Fundação Getulio Vargas (FGV). E-mail: rafael.alcadipani@fgv.br 